\title{
Subclinical Hypothyroidism: Prevalence, Health Impact, and Treatment Landscape
}

\author{
Won Sang Yoo, Hyun Kyung Chung \\ Division of Endocrinology and Metabolism, Department of Internal Medicine, Dankook University College of Medicine, \\ Cheonan, Korea
}

Subclinical hypothyroidism (sHypo) is defined as normal serum free thyroid hormone levels coexisting with elevated serum thyroidstimulating hormone (TSH) levels. sHypo is a common condition observed in clinical practice with several unique features. Its diagnosis should be based on an understanding of geographic and demographic differences in biochemical criteria versus a global reference range for TSH that is based on the $95 \%$ confidence interval of a healthy population. During the differential diagnosis, it is important to remember that a considerable proportion of sHypo cases are transient and reversible in nature; the focus is better placed on persistent or progressive forms, which mainly result from chronic autoimmune thyroiditis. Despite significant evidence documenting the health impacts of sHypo, the effects of levothyroxine treatment (LT4-Tx) in patients with sHypo remains controversial, especially in patients with grade $1 \mathrm{sHypo}$ and older adults. Existing evidence suggests that it is reasonable to refrain from immediate LT4-Tx in most patients if they are closely monitored, except in women who are pregnant or in progressive cases. Future research is needed to further characterize the risks and benefits of LT4-Tx in different patient cohorts.

Keywords: Subclinical hypothyroidism; Diagnosis; Prevalence; Treatment

\section{INTRODUCTION}

The definition of subclinical hypothyroidism (sHypo) is biochemical in nature, namely elevated serum thyroid-stimulating hormone (TSH) levels combined with normal levels of serum free thyroid hormones (i.e., within the population reference range) [1]. Unlike overt hypothyroidism, patients with sHypo may present without any clinical features of hypothyroidism and are often identified through routine health examinations. It is a challenge to determine the clinical meaning of this "subclinical" state [2].

Clinically, there are several important aspects of sHypo to consider, including the diagnosis. The normal range for TSH is

Received: 17 April 2021, Revised: 8 May 2021, Accepted: 10 May 2021

Corresponding author: Hyun Kyung Chung

Department of Internal Medicine, Dankook University College of Medicine,

201 Manghyang-ro, Dongnam-gu, Cheonan 31116, Korea

Tel: +82-41-550-3057, Fax: +82-41-556-3256,

E-mail: chkendo@dankook.ac.kr determined based on the $95 \%$ confidence interval of the healthy population (i.e., the reference population). Patient demographics or characteristics (e.g., age, sex, race, iodine intake, and pregnancy) can affect the upper limit of normal (ULN) for TSH [3]. Additionally, there are individual variations of the hypothalamus-thyroid axis set-point [4] that lead to patient-specific thresholds for sHypo status. Another key sHypo-related clinical aspect is the wide range of effects of thyroid hormone on various organs - in particular, the role of thyroid hormone in cardiovascular and cognitive function makes the potential health effects of sHypo worrisome. For an endocrinologist, sHypo-related health issues may focus solely on the thyroid itself, leading to several important questions: (1) is the occurrence a transient

\section{Copyright $\odot 2021$ Korean Endocrine Society}

This is an Open Access article distributed under the terms of the Creative Commons Attribution Non-Commercial License (https://creativecommons.org/ licenses/by-nc/4.0/) which permits unrestricted non-commercial use, distribution, and reproduction in any medium, provided the original work is properly cited. 
or persistent phenomenon, (2) what are the cause(s), (3) what is the risk of progression to overt disease, and (4) what should be done to address the health of the patient's thyroid? While the most important issue may be the decision of whether to initiate levothyroxine treatment (LT4-Tx), the existing evidence is not clear-cut, making clinical decisions such as when to treat and the best course of follow-up challenging and a matter of debate.

In this review, recent clinical and epidemiological data for sHypo are introduced to discuss: (1) the diagnosis and prevalence of sHypo, (2) its natural course and etiology, (3) its health impact, and (4) treatment recommendations.

\section{DIAGNOSIS AND PREVALENCE OF sHypo}

sHypo is a common disease with a reported overall prevalence of $3.1 \%$ in Korea (males 2.26\%, females 4.04\%; Korean National Health and Nutrition Examination Survey [KNHANES VI]), $4.3 \%$ in the USA (National Health and Nutrition Examination Survey [NHANES] III) [5,6], and as high as $20 \%$ depending on the study population [7]. In fact, the prevalence might be even higher than estimated as a considerable proportion of the population may have undiagnosed sHypo [8]. The reported prevalence of sHypo in different countries is presented in Table 1 [5,6,8-14]. Several factors may influence differences in prevalence. First, the normal range of serum TSH could vary across different countries or ethnic groups [15]. The mean level and ULN of serum TSH are 2.16 and $7.03 \mathrm{mIU} / \mathrm{L}$, respectively, in Koreans (KNHANES), whereas the corresponding levels are 1.40 and $4.12 \mathrm{mIU} / \mathrm{L}$, respectively, in the USA (NHANES III) $[6,16]$. The markedly higher levels of TSH in Koreans may be explained by the excess iodine intake or genetic differences in the TSH set-point [16] and this discrepancy provides a clear example of why a single international cut-off for TSH cannot be recommended for the diagnosis of sHypo. Age is another important factor to consider; serum TSH levels increase with age, meaning that a mild increase may be normal for older individuals [17]. Therefore, using a single ULN for TSH for all age groups may lead to the misclassification of elderly individuals as having sHypo, which in turn could impact prevalence estimates. Importantly, age-related differences vary by country; the TSH median and 97.5th percentile increased progressively with age in the United States population [18], but in Koreans, the $\mathrm{TSH}$ and age graph was U-shaped (higher in younger and older subjects) [19,20]. Certain other factors (e.g., pregnancy, obesity, and dwelling conditions) can also impact the TSH reference range. TSH levels are usually lower during pregnancy, especially in the first trimester, and gradually rise in the second and third trimesters [21]. The extent of this reduction varies significantly based on race and country. Compared to Western countries, Asian countries, including China and Korea, show a modest reduction in the ULN of TSH during the first trimester $[22,23]$. Thus, most guidelines recommend developing population-based, age-specific, and trimester-specific reference ranges for serum TSH based on local data [21].

When age and race-specific reference ranges for TSH are not available, the ULN for TSH can be considered 4.0 to $6.0 \mathrm{mIU} / \mathrm{L}$. sHypo is often classified as grade 1 (TSH level between the ULN and $9.9 \mathrm{mIU} / \mathrm{L}$ ) and grade 2 (TSH levels $10 \mathrm{mIU} / \mathrm{L}$ or higher) [24]. Grade 1 can also be subdivided into those with TSH levels below 7 and between 7.0 and $9.9 \mathrm{mIU} / \mathrm{L}$ in younger

\begin{tabular}{|c|c|c|c|c|c|c|}
\hline \multirow{2}{*}{ Year } & \multirow{2}{*}{ Country } & \multirow{2}{*}{ Age, yr } & \multirow{2}{*}{$\begin{array}{l}\text { TSH threshold, } \\
\text { mIU/L }\end{array}$} & \multicolumn{2}{|c|}{ Prevalence, $\%$} & \multirow{2}{*}{ Reference } \\
\hline & & & & Women & Men & \\
\hline 1977 & UK (the Whickham survey) & $>18$ & $>6.0$ & 7.5 & 2.8 & [9] \\
\hline 1981 & Sweden (women only) & $44-66$ & $8.0-14.4$ & 5.1 & & {$[10]$} \\
\hline 1990 & USA (nursing home) & $>60$ & $>4.5$ & 14.6 & 9.7 & {$[11]$} \\
\hline 1993 & Japan (health examination) & Mean 46 & $>5.0$ & 2.1 & 0.4 & {$[12]$} \\
\hline 2000 & USA (the Colorado study) & $\geq 18$ & $>5.1$ & \multicolumn{2}{|c|}{9.1 (men and women) } & {$[13]$} \\
\hline 2002 & USA (NHANES III) & $\geq 12$ & $>4.5$ & \multicolumn{2}{|c|}{4.3 (men and women) } & {$[6]$} \\
\hline 2006 & The Netherlands & $>18(46 \%>69)$ & $>4.0$ & 4.9 & 3.0 & {$[14]$} \\
\hline 2017 & South Korea (KNHANES VI) & $\geq 10$ & $>6.86$ & 4.0 & 2.3 & {$[5]$} \\
\hline 2019 & Europe (meta-analysis) & & $>4.5$ & 4.8 & 2.7 & {$[8]$} \\
\hline
\end{tabular}

TSH, thyroid-stimulating hormone; NHANES, National Health and Nutrition Examination Survey; KNHANES, Korean National Health and Nutrition Examination Survey. 
patients ( $<65$ years) for classifying the benefit of LT4-Tx [25]. Most patients with sHypo (90\%) have serum TSH levels below $10 \mathrm{mIU} / \mathrm{L}$ (i.e., grade 1).

Another factor to consider in the differential diagnosis for sHypo is the presence of inter-individual differences in the TSH set-point [26]. Everyone has a unique set-point of the hypothalamic-pituitary-thyroid axis, which is genetically determined [4]. This concept is useful for explaining the different signs and symptoms of patients who have the same level of TSH. Theoretically, it is possible that a particular TSH level may be abnormal for one individual's set-point, but still be within the normal reference limit. Therefore, it would be important to interpret sHypo-relevant laboratory data considering not only the fixed TSH level, but also serial changes in TSH levels concurrently with a careful clinical assessment.

\section{NATURAL COURSE AND ETIOLOGY OF sHypo}

Although the rate of progression to overt hypothyroidism may vary depending on several factors [27], it is not high in those with grade 1 sHypo (2\% to $4 \%$ per year) [3]. For women with positive thyroid peroxidase antibodies (TPOAbs) and a baseline TSH between 2.5 and $4 \mathrm{mIU} / \mathrm{L}$, the risk of progression to overt hypothyroidism is roughly $1 \%$ per year [28]. In children and ad- olescents, chronic autoimmune thyroiditis (CAT) usually remains static for years and recovery is more common [29]. Without considering causative factors, the overall recovery rate for grade $1 \mathrm{sHypo}$ is $30 \%$ over 3 years and $60 \%$ over 5 years [3,30]. These data reveal that there are many patients with transient sHypo. In response to various external and internal stimuli, serum TSH levels could change transiently without thyroid diseases. Iodine or food with high iodine levels, medications, or testing reagents are classic examples of external stimuli [16,31]. Serum TSH concentrations could fluctuate as a result of diurnal or seasonal variations [32,33], and transiently increase during the course of non-thyroidal illness or with several drugs. In patients who are taking LT4, an inadequate dosage or consumption of substances that prevent absorption or increase the clearance of LT4 could also lead to sHypo. In these transient cases, only a re-evaluation of thyroid function without LT4-Tx could be recommended [34]. Thus, the first step of sHypo management is to confirm the persistence of TSH elevation and exclude transient cases. The causative factors of sHypo are summarized in Table 2.

Persistent sHypo mainly implies CAT, and the tendency for progression to overt hypothyroidism might be related to the degree of immunological deterioration and thyroid reserve. The most important risk factors have been shown to be serum TSH levels and TPOAb positivity [35]. Higher TSH levels are asso-

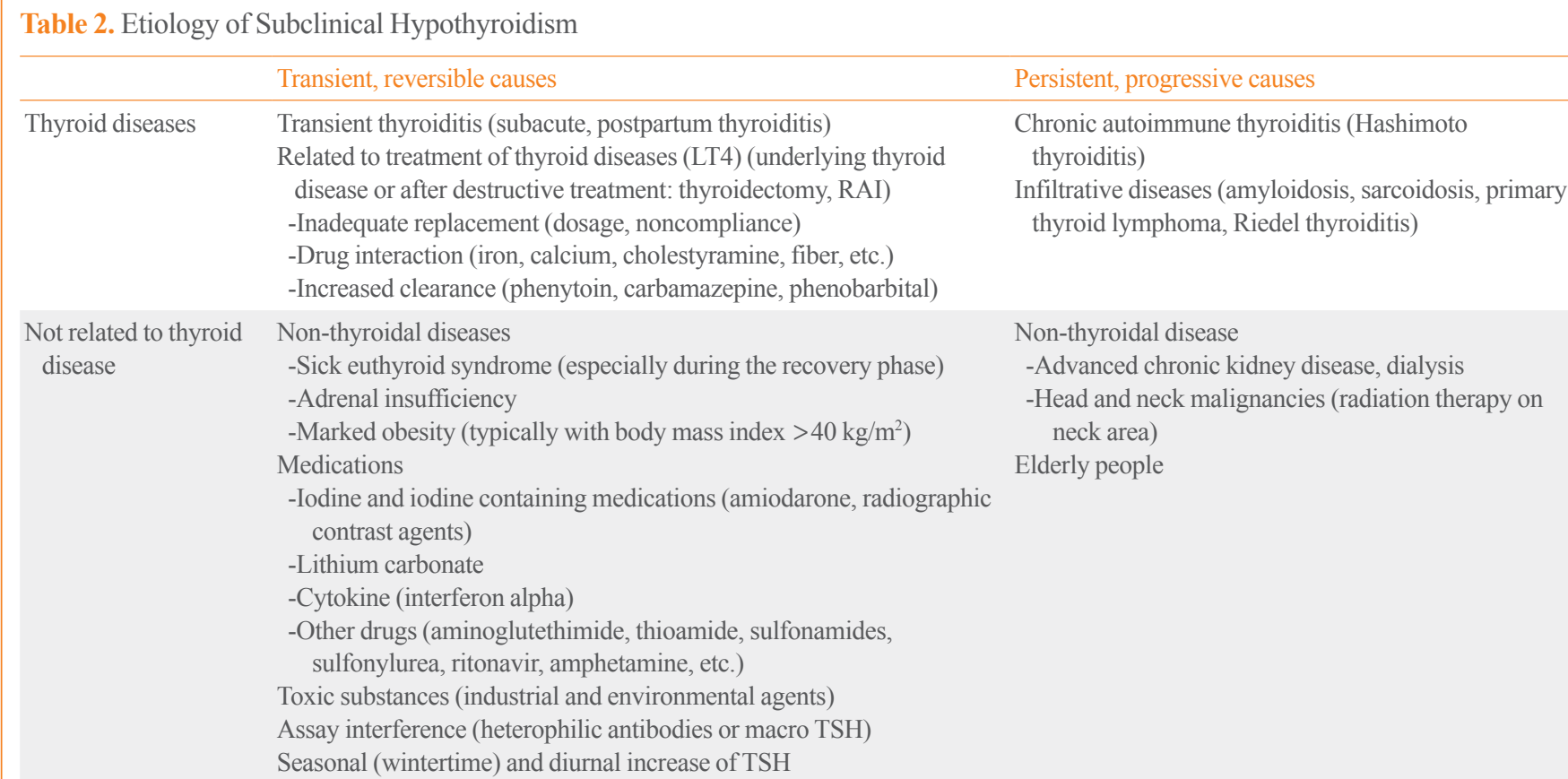

Persistent, progressive causes

Chronic autoimmune thyroiditis (Hashimoto thyroiditis)

Infiltrative diseases (amyloidosis, sarcoidosis, primary thyroid lymphoma, Riedel thyroiditis)

Non-thyroidal disease

-Advanced chronic kidney disease, dialysis

-Head and neck malignancies (radiation therapy on neck area)

Elderly people

LT4, levothyroxine; RAI, radioactive iodine; TSH, thyroid-stimulating hormone. 
ciated with a higher rate of TPOAb positivity, especially in women [6,28]. In patients with existing thyroid disease [36] or without a history of thyroid disease, prospective studies demonstrated that the most important predictor of progression was the serum TSH concentration [37]. In addition, iodine intake [38], cigarette smoking [39], racial differences [6], and cold environmental temperatures [33] have been identified as risk factors. Thyroid sonographic findings, such as markedly decreased echogenicity and multifocal pseudonodular hypoechoic infiltration, could also be used as indicators of inflammatory activity in CAT [40]. There is no evidence that early LT4-Tx would help prevent the development of overt hypothyroidism. Thus, in terms of progression to overt hypothyroidism, the "wait and see" strategy would be acceptable in most individuals with sHypo (grade 1), especially in TPOAb-negative patients.

\section{GENERAL CONSIDERATIONS FOR THE APPROACH TO sHypo}

\section{Age}

The aging process plays an important role in thyroid anatomy and physiology. Anatomical changes with aging include reduction in weight of the gland and the size of follicles, as well as increased fibrosis and lymphocytic infiltration. The half-life of thyroid hormone slightly increases with age and its synthesis itself could decrease, although this is not a known contributor to thyroid dysfunction except in cases of existing thyroid disease [41]. If the global ULN of TSH was used for all age groups, the prevalence of sHypo would be increased in the elderly population [42]. The rate of TPOAb positivity also increases with age in the healthy population without thyroid disease and decreases again in those 80 years or older [41].

In the elderly population, CAT is also the most common cause of sHypo [43]. Since the manifestations may be erroneously ignored as the effect of aging, sHypo may remain unrecognized, especially since the decline in thyroid function is gradual. Previous studies found that older adults with persistent sHypo did not have elevated risks of coronary heart disease, heart failure, cardiovascular death [44], or cognitive dysfunction [45]. In a recent double-blind, randomized, placebo-controlled trial (the Thyroid hormone Replacement for Untreated older adults with Subclinical hypothyroidism-a randomized placebo-controlled Trial [TRUST]), LT4-Tx showed no benefits in older patients with mild sHypo [46]. Furthermore, polypharmacy and the risk of LT4 overtreatment are non-negligible concerns, especially in frail, elderly patients. Altogether, a conservative approach to the management of sHypo (i.e., without LT4-Tx) could be the most reasonable and safest choice in elderly patients with sHypo.

In children, thyroid hormone has unique roles, such as exerting a maturational effect on brain development in the first 3 years of life, and its effects on linear growth persist until epiphyseal closure in adolescence. The causes of sHypo are more likely to be idiopathic or genetic in younger children versus CAT in adolescents [47]. In iodine-rich areas, excess iodine could be associated with sHypo in children [48]. In general, sHypo in children is a benign and self-remitting condition [49]. Most children with sHypo are usually asymptomatic and there is no known association with adverse effects on growth or bone health [47]. The risk of progression to overt hypothyroidism seems to be negligible in idiopathic and mild cases of sHypo in children [50], although the risk of deterioration of thyroid function is somewhat higher in CAT-related sHypo [51,52]. Because of the lack of high-quality studies or consensus guidelines, it remains a matter of debate whether to treat children with sHypo [53]. Starting LT4-Tx only in sHypo infants $>1$ month until 3 years of age is recommended based on concerns related to thyroid-dependent brain development [47]. Regular (every 6 to 12 months) monitoring of TSH with TPOAb would be needed in cases of sHypo due to CAT, and LT4-Tx should be strongly considered in patients with a TSH level > $10 \mathrm{mIU} / \mathrm{L}$ [47].

\section{Sex}

The prevalence of sHypo is higher in women than in men [6], due in part to the higher prevalence of CAT in women and higher estrogen levels [54]. During pregnancy, metabolic needs increase, which leads to changes in the thyroid-pituitary axis [55]. Reduction of the lower and upper limit of TSH is a hallmark of pregnancy, typically in the first trimester, as a result of the elevated serum human chorionic gonadotropin levels directly stimulating the TSH receptor [56]. During the second and third trimesters, the TSH reference range increases, although it remains lower than in healthy non-pregnant women [57]. The extent of this reduction varies across different ethnic groups and according to iodine intake status. Thus, if possible, it is strongly recommended to define population-based, trimester-specific reference ranges for serum TSH through local population data [21]. If not available, it is typical to set the ULN of TSH as 0.1 to 2.5 $\mathrm{mIU} / \mathrm{L}$ in the first trimester, 0.3 to $3.0 \mathrm{mIU} / \mathrm{L}$ in the second trimester, and 0.3 to 3.0 or $3.5 \mathrm{mIU} / \mathrm{L}$ in the third trimester. sHypo during pregnancy is defined using TSH ULNs of $>2.5 \mathrm{mIU} / \mathrm{L}$ in the first trimester, $>3.0 \mathrm{mIU} / \mathrm{L}$ in the second trimester, and $>3.0$ or $3.5 \mathrm{mIU} / \mathrm{L}$ in the third trimester [57]. The latest Ameri- 
can Thyroid Association guidelines recommend that the ULN in pregnancy could be calculated by subtracting $0.5 \mathrm{mIU} / \mathrm{L}$ from the non-pregnant reference range [21].

Overt hypothyroidism during pregnancy should be considered a dangerous condition to both the mother and fetus. sHypo during pregnancy is also associated with multiple adverse maternal and neonatal outcomes [58]. Almost all studies have demonstrated an increased risk of pregnancy-specific complications (e.g., pregnancy loss, preterm delivery, and placental abruption) associated with elevated maternal TSH concentrations [21,59]. These outcomes are even worse in the presence of TPOAb. Thus, a more aggressive approach with LT4-Tx would be recommended in pregnant women [21]. Based on concerns of the adverse effects on pregnancy, it would be better to manage sHypo aggressively in women who are undergoing in vitro fertilization or planning to conceive, or even in all women of childbearing age [21]. Although the value of LT4-Tx in preventing adverse outcomes remains uncertain, sHypo detected before conception should be treated, and doing so may also be considered in the first trimester [47].

\section{Symptoms}

Fatigue, muscle weakness, weight gain, cold intolerance, and constipation have been reported as sHypo symptoms [13]. Mild memory impairment and mood changes have been identified in middle-aged patients with grade 2 sHypo [60]. Functional magnetic resonance imaging suggested that working memory may be impaired in individuals with sHypo [61]. However, a small proportion of asymptomatic sHypo subjects have superior wellbeing compared with euthyroid individuals as assessed using general health questionnaires and neuropsychological tests [62]. In a meta-analysis, the risk of depression in individuals with sHypo was significantly higher than in their euthyroid counterparts [63], while other studies only confirmed this relationship in younger patients [64-66]. Yet another study identified no link between depression and sHypo in young and middle-aged adults [67].

When managing patients with psychoneurotic symptoms, there are several points to remember. First, it should be kept in mind that these symptoms (e.g., fatigue, depression, weakness) are extremely common in the general population (especially elderly patients), meaning that their presence in an individual can be distinct from sHypo. A second point to consider is the "labeling effect," whereby patients who learn about their thyroid condition are more likely to report related symptoms. This observation is supported by findings from a population-based study suggesting that there was no correlation between thyroid function and self-reported depression overall, but that within the subgroup with known thyroid disease, there was an increased prevalence of depression, even in those with normal TSH levels [68].

Previous treatment guidelines have recommended the use of LT4-Tx based mainly on symptoms and serum TSH levels (Table 3); however, recent data are not consistent with these recommendations. A systematic review and meta-analysis failed to find an effect of LT4-Tx on symptomatic improvement [69]. In a prospective analysis involving adults with sHypo aged 80 years and older, LT4-Tx was not significantly associated with improvement in hypothyroid symptoms or fatigue [70]. As mentioned above, the TRUST study also found no benefit of LT4-Tx on thyroid-related symptoms in elderly people with mild sHypo [46]. Altogether, the timing of LT4-Tx initiation should be carefully considered in relation to symptomatic improvement, especially in elderly patients with mild sHypo.

On physical examination, the presence of goiter could be a clue suggesting CAT, although CAT may also present without goiter [71]. To rule out other causes, it is recommended to measure serum TPOAb and check the history of the goiter, its size, and the co-occurrence of symptoms (e.g., pain).

\section{ORGAN-SPECIFIC CONSIDERATIONS IN THE MANAGEMENT OF sHypo}

\section{Cardiovascular function}

Doppler echocardiographic data demonstrated that sHypo is related to left ventricular (LV) diastolic function, a slowed rate of relaxation time, and impaired ventricular filling (exercise), leading to LV systolic dysfunction [72]. Vascular abnormalities have also been reported in patients with sHypo [73]. Grade 2 sHypo was found to be associated with increased carotid intima-media thickness in a meta-analysis [74]. However, clinical data are not consistent with these laboratory and diagnostic findings. Several studies found correlations between sHypo and cardiovascular disease $[75,76]$, including a comprehensive meta-analysis that demonstrated an association between cardiovascular disease risk and sHypo [77]. Long-term cardiovascular outcomes after coronary bypass grafting in patients with sHypo showed a poor prognosis [78]. However, data from a consortium of cohort studies with data from more than 75,000 participants (Thyroid Studies Collaboration) revealed no correlation with the risk of atrial fibrillation [79], heart failure [80], stroke [81], coronary heart disease [82], mortality [83], and sHypo. Only in a sub- 


\begin{tabular}{|c|c|c|c|}
\hline & Consider LT4-Tx & Observe without LT4-Tx & Reference \\
\hline $\begin{array}{l}\text { American Thyroid } \\
\text { Association (2012) }\end{array}$ & $\begin{array}{l}\text { TSH }>10 \mathrm{mIU} / \mathrm{L} \text {, age }<70 \text { years } \\
\text { TSH } 4-10 \mathrm{mIU} / \mathrm{L} \text {, age }<65 \text { years with symptoms }\end{array}$ & $\begin{array}{l}\mathrm{TSH}<10 \mathrm{mIU} / \mathrm{L} \text {, age }<70 \text { years } \\
\mathrm{TSH} 4-10 \mathrm{mIU} / \mathrm{L} \text {, age }>65 \text { years }\end{array}$ & {$[100]$} \\
\hline $\begin{array}{l}\text { European Thyroid } \\
\text { Association (2013) }\end{array}$ & $\begin{array}{l}\text { TSH }>10 \mathrm{mIU} / \mathrm{L}, \text { age }<70 \text { years } \\
\text { TSH }<10 \mathrm{mIU} / \mathrm{L} \text {, age }<70 \text { years with symptoms } \\
\text { TSH }>10 \mathrm{mIU} / \mathrm{L} \text {, age }>70 \text { years with clear } \\
\text { symptoms or high cardiovascular risk }\end{array}$ & $\begin{array}{l}\text { TSH }<10 \mathrm{mIU} / \mathrm{L} \text { without symptoms, age }<70 \text { years } \\
\text { TSH }<10 \mathrm{mIU} / \mathrm{L} \text {, age }>70 \text { years }\end{array}$ & [101] \\
\hline $\begin{array}{l}\text { Clinical practice guideline } \\
\text { (2017) }\end{array}$ & $\begin{array}{l}\text { TSH }>10 \mathrm{mIU} / \mathrm{L}, \text { age }<70 \text { years } \\
\text { Especially, symptoms }(+) \text {, cardiac risk factors }(+) \\
6 \text { months } \mathrm{LT} 4-\mathrm{Tx} \text { trial }(\text { may) } \\
\text { TSH }>4.5 \text { to }<7 \mathrm{mIU} / \mathrm{L} \text { with symptoms } \\
\text { TSH }>7 \text { to }<10 \mathrm{mIU} / \mathrm{L} \text {, age }<70 \text { years, with } \\
\text { symptoms regardless of age, cardiac risk factors, } \\
\text { TPOAb }(+)\end{array}$ & $\mathrm{TSH}>10 \mathrm{mIU} / \mathrm{L}$, age $>70$ years & {$[24]$} \\
\hline UpToDate (2018) & $\begin{array}{l}\text { TSH }<7 \mathrm{mIU} / \mathrm{L} \text {, age }<65 / 70 \text { years with symptoms } \\
\text { TSH } 7-10 \mathrm{mIU} / \mathrm{L} \text {, age }<65 \text { years } \\
\text { TSH } 7-10 \mathrm{mIU} / \mathrm{L} \text {, age }>65 / 70 \text { years with symptoms } \\
\text { TSH }>10 \mathrm{mIU} / \mathrm{L}\end{array}$ & $\begin{array}{l}\text { TSH }<7 \mathrm{mIU} / \mathrm{L} \text {, age }>65 / 70 \text { years } \\
\text { TSH }<7 \mathrm{mIU} / \mathrm{L} \text {, age }<65 / 70 \text { years without symptoms } \\
\text { TSH } 7-10 \mathrm{mIU} / \mathrm{L} \text {, age }>65 / 70 \text { years without } \\
\text { symptoms }\end{array}$ & [102] \\
\hline $\begin{array}{l}\text { National Institute for Health } \\
\text { and Care Excellence } \\
\text { (NICE) guidelines (2018) }\end{array}$ & $\begin{array}{l}\text { TSH }>10 \mathrm{mIU} / \mathrm{L} \text {, age }<70 \text { years } \\
\text { TSH } 4-10 \mathrm{mIU} / \mathrm{L} \text {, age }<65 \text { years with symptoms }\end{array}$ & $\begin{array}{l}\text { TSH }>10 \mathrm{mIU} / \mathrm{L} \text {, age }>70 \text { years } \\
\text { TSH } 4-10 \mathrm{mIU} / \mathrm{L} \text {, age }>65 \text { years }\end{array}$ & {$[103]$} \\
\hline $\begin{array}{l}\text { Clinical practice guideline } \\
\text { (2019) }\end{array}$ & $\begin{array}{l}\text { Only women who are or trying to become pregnant } \\
\text { or patients with TSH }>20 \mathrm{mIU} / \mathrm{L}\end{array}$ & Almost all adults & [104] \\
\hline
\end{tabular}

analysis, higher cardiovascular risk was associated with the severity of sHypo and the presence of TPOAb [25].

The effects of LT4-Tx on cardiovascular outcomes are also inconclusive. In a retrospective study, LT4-Tx reduced the risk of coronary heart disease events [84], but other studies failed to confirm improvement of the LV ejection fraction after 52 weeks of LT4-Tx in patients with sHypo and acute myocardial infarction [85]. Although the TRUST study failed to confirm a positive effect of LT4-Tx on the occurrence of serious cardiovascular events, such as atrial fibrillation and heart failure [46], it focused only on elderly patients, and participants with TSH $>10$ $\mathrm{mIU} / \mathrm{L}$ accounted for only $5 \%$ of the study population. Therefore, it would be inappropriate to extrapolate the TRUST data to subjects with grade 2 sHypo and those who are $<65$ years old. Based on the results available to date, it may be reasonable to pay additional attention to patients with grade 2 sHypo at high risk of cardiovascular disease; however, existing evidence assessing the therapeutic effects of LT4-Tx on cardiovascular risk is not yet sufficient. Further large, prospective multi-center studies are needed to assess the usefulness of LT4-Tx for preventing cardiovascular disease in sHypo, especially in younger patients.

\section{Cognitive function}

When a clinician faces a patient with sHypo and symptoms of dementia, the question may arise of whether a link exists between these two conditions. In a population-based cohort of elderly people, sHypo was not associated with mild cognitive impairment $[66,86]$. In another meta-analysis, no correlation was found between sHypo and cognitive impairment in individuals younger than 75 years who had higher TSH concentrations [45]. sHypo demonstrated no association with a faster decline in Mini-Mental State Examination scores over time [87]. Another systematic review found no evidence of an association between sHypo and cognitive impairment in people over 60 years [88]. Thus, there is a shortage of evidence to support a correlation between sHypo and cognitive dysfunction. LT4-Tx cannot yet be justified as a treatment to improve cognitive function, especially in elderly people.

\section{Musculoskeletal, kidney, and liver functions}

Unlike subclinical hyperthyroidism, which has a significant impact on fracture risk, a meta-analysis found no association between sHypo and fracture risk [89]. Additionally, no association has been reported between sHypo and serial bone mineral den- 
sity measurements [90] or bone turnover markers and bone loss [91]. In a cross-sectional, prospective study that assessed the associations of subclinical thyroid dysfunction with frailty and the five frailty subdomains (sarcopenia, weakness, slowness, exhaustion, and low activity), sHypo was not consistently associated with the overall frailty components [92]. A randomized controlled study, the Prospective Study of Pravastatin in the Elderly at Risk (PROSPER), found no evidence that sHypo contributes to decreased functional capacity [93]. Altogether, sHypo is thought to have no correlation with the deterioration of musculoskeletal function.

In end-stage renal disease, a higher prevalence of sHypo has been noted compared with the general population [94]. In patients with sHypo and chronic kidney disease (CKD), LT4-Tx attenuated the decline in renal function [95]. sHypo was associated with higher mortality than the euthyroid state in patients with renal failure requiring hemodialysis [96]. These results demonstrated that sHypo worsens the clinical course of CKD. However, a meta-analysis found no correlation between sHypo and decline in kidney function [97].

Overt hypothyroidism is known to be associated with the presence and severity of nonalcoholic fatty liver disease (NAFLD); however, evidence of an association between NAFLD and SHypo is insufficient to date. In a cross-sectional study, individuals with sHypo and fatty liver had higher risks for metabolic syndrome, insulin resistance, and a higher coronary artery calcification score than those with sHypo and no fatty liver [98]. In another small-scale, randomized controlled trial, LT4-Tx demonstrated benefits on NAFLD in sHypo patients with dyslipidemia [99]. Larger-scale, well-designed prospective studies to confirm the correlation between sHypo and liver function are required.

\section{MANAGEMENT OF sHypo}

Several clinical guidelines have provided a path for clinical decision-making for sHypo (Table 3) [24,100-104]. These guidelines primarily integrate patient age and serum TSH levels. Other parameters such as the presence of TPOAb, symptoms, cardiac risk factors, and goiter also be included for reference. Even with these guidelines, however, clinicians are often confronted with difficult challenges in the management of sHypo. Since the guidelines do not apply age-adjusted reference ranges of TSH, the suboptimal use of a single TSH cut-point value may still be applied to patients. Although the adverse health impacts of sHypo have been reported, data confirming the benefits of LT4-Tx remain unclear [101]. When using LT4-Tx, the appropriate du- ration of treatment has not yet been empirically defined. When managing patients without LT4-Tx, the ideal duration and schedule of follow-up have likewise not been clearly defined. The cost-benefit effect or possible risks of LT4-Tx in sHypo are also unclear. The remaining uncertainties have caused persistent concerns and dissatisfaction among patients, regardless of whether they are treated.

Based on the paucity of high-quality evidence, a clear-cut path for all sHypo patients cannot be provided at this moment. However, in clinical situations, it is essential to stratify patients depending on their need for LT4-Tx and the appropriate approach to monitoring, including the cadence of visits. In this review, a recommendation is suggested based on the intensity of the intervention: conservative, aggressive, or intermediate (Table 4). These recommendations have been devised to guide management decisions. In the conservative approach, LT4-Tx could be postponed for a while, even up to a transition into the overt hypothyroid state, and the follow-up schedule could be less frequent. In contrast, in the aggressive approach, LT4-Tx should be applied not too late, and a tight follow-up schedule should be considered. The intermediate approach falls in between the other two approaches, but is closer to the conservative approach due to a lack of definitive evidence; the LT4-Tx and follow-up schedule could be decided based on discussions with patients. Exceptional cases and educational factors are also included.

A representative example of the conservative approach is furnished by elderly patients; there is no need to rush to treatment in elderly patients with sHypo. As reviewed above, the serum TSH level could rise with increasing age as a result of physiological adaptation [17]. The upper limit of the $95 \%$ confidence interval is around $6.0 \mathrm{mIU} / \mathrm{L}$ in $>80$-year-old untreated individuals and could reach up to $8.0 \mathrm{mIU} / \mathrm{L}$ in those over 90 [18]. Elderly patients are also more vulnerable to LT4 overtreatment with increased risks of atrial fibrillation, ischemic heart disease, and fractures $[3,105,106]$. The recent TRUST trial has provided relatively clear evidence suggesting an absence of benefits of LT4-Tx in older individuals with sHypo [46]. Thus, "wait-andsee' is a wise strategy, especially in frail patients. LT4-Tx could be considered in those with grade 2 sHypo (TSH $>10 \mathrm{mIU} / \mathrm{L}$ ) and relatively young patients ( 65 to 70 years), but patients' life expectancy and the presence of comorbid conditions should also be considered [101]. When treatment is initiated, a "start low, go slow" policy is recommended [101], starting with a low dose of LT4 (12.5 to $25 \mu \mathrm{g} /$ day and slowly increased by 12.5 to $25 \mu \mathrm{g}$ /day every 4 to 8 weeks). 
Table 4. Recommendation of LT4-Tx in Patients with Subclinical Hypothyroidism

(1) Elevated serum TSH, normal free T4-Repeat TSH measurement 1-3 months later (in cases of pregnancy, repeat within a few days)

(2) Differential diagnosis (DDx) - Focus on the persistent, progressive causes vs. transient, reversible causes

- During pregnancy, correct sHypo first, regardless of the causative factors

(3) Approaches in the management of persistent sHypo

\begin{tabular}{|c|c|c|c|}
\hline & Conservative & Aggressive & Intermediate \\
\hline Representative case & Elderly patients & Women related to pregnancy ${ }^{\mathrm{a}}$ & All other cases \\
\hline Main policy of management & Wait-and-see & Consider LT4-Tx & Case by case (mainly, wait-and-see) \\
\hline \multirow[t]{2}{*}{ UNL of TSH } & $\begin{array}{l}\text { If possible, use the population-based, } \\
\text { age-specific ULN }\end{array}$ & $\begin{array}{l}\text { If possible, use the population-based, } \\
\text { trimester (TM)-specific ULN } \\
\text { (during pregnancy) }\end{array}$ & $\begin{array}{l}\text { If possible, use the population-based, } \\
\text { age-specific ULN }\end{array}$ \\
\hline & $\begin{array}{l}\text { If unavailable, } \\
\text { TSH 4-9.9 mIL/L (grade 1) } \\
\text { TSH } \geq 10 \mathrm{mIL} / \mathrm{L} \text { (grade 2) }\end{array}$ & $\begin{array}{l}\text { If unavailable, (during pregnancy) } \\
\text { 1st TM } 0.1-2.5 \mathrm{mIL} / \mathrm{L} \\
\text { 2nd TM } 0.3-3.0 \mathrm{mIL} / \mathrm{L} \\
\text { 3rd TM } 0.3-3.0 \text { or } 3.5 \mathrm{mIL} / \mathrm{L}\end{array}$ & $\begin{array}{l}\text { If unavailable, } \\
\text { TSH 4-9.9 mIL/L (grade 1) } \\
\text { TSH } \geq 10 \mathrm{mIL} / \mathrm{L} \text { (grade } 2 \text { ) }\end{array}$ \\
\hline Follow-up schedule of TFT & Go slow (3-6 months) & $\begin{array}{l}\text { Could be a tight schedule depending } \\
\text { on LT4-Tx }\end{array}$ & $\begin{array}{l}\text { Case by case (mainly, go slow: 3-6 } \\
\text { months) }\end{array}$ \\
\hline Exceptions & $\begin{array}{l}\text { (may) Consider LT4-Tx trial in less } \\
\text { old (65-75 years), non-frail, grade } \\
\text { 2, progressive case, risk of CVD } \\
\text { (e.g., heart failure), and patient's } \\
\text { willing }\end{array}$ & $\begin{array}{l}\text { (may) Consider 'wait-and-see' } \\
\text { without LT4-Tx in case of transient } \\
\text { sHypo, mild sHypo in third } \\
\text { trimester, women under birth } \\
\text { control }\end{array}$ & $\begin{array}{l}\text { (may) Consider LT4-Tx trial in } \\
\text { progressive cases, large goiter, } \\
\text { grade 2, positive TPOAb, CVD } \\
\text { risks, genetic causes (children) and } \\
\text { patients' willing }\end{array}$ \\
\hline LT4-Tx & $\begin{array}{l}\text { Start with lower than usual dosage } \\
(12.5-25 \mu \mathrm{g} / \text { day }) \text { and tighter } \\
\text { schedule of TFT }\end{array}$ & $\begin{array}{l}\text { Could start with higher dosage than } \\
\text { usual, if needed }\end{array}$ & $\begin{array}{l}\text { Start with lower or usual dosage ( } 50 \\
100 \mu \mathrm{g} / \text { day) and tighter schedule of } \\
\text { TFT }\end{array}$ \\
\hline Duration of LT4-Tx & $\begin{array}{l}\text { No definite criteria (6 months trial } \\
\text { and re-evaluation) }\end{array}$ & Up to the end-point of pregnant issue & $\begin{array}{l}\text { No definite criteria (6 months trial } \\
\text { and re-evaluation) }\end{array}$ \\
\hline Education & \multicolumn{3}{|c|}{$\begin{array}{l}\text { 1. In case of CAT, education about the iodine restriction is essential, especially iodine replete area. } \\
\text { 2. In women of child-bearing age, education about the necessity of planned pregnancy is essential. } \\
\text { 3. In wait-and-see cases, education about the symptoms of hypothyroidism would be needed not to miss the overt } \\
\text { hypothyroidism. } \\
\text { 4. In LT4-Tx cases, education about the symptoms of hyperthyroidism would be needed not to miss the overtreatment. }\end{array}$} \\
\hline
\end{tabular}

LT4-Tx, levothyroxine treatment; TSH, thyroid-stimulating hormone; T4, thyroxine; sHypo, subclinical hypothyroidism; UNL, upper normal limit; TFT, thyroid function test; CVD, cardiovascular disease; TPOAb, thyroid peroxidase antibody; CAT, chronic autoimmune thyroiditis.

${ }^{a}$ Women related to pregnancy contain maternity, women who wishing baby, under IVF or women of child-bearing age.

Pregnant women provide a representative example of the aggressive approach. Based on population-based, trimester-specific reference ranges for serum TSH [21], if possible, LT4-Tx should be considered in pregnant sHypo patients, regardless of etiologic factors. LT4-Tx is strongly recommended in women who are: (1) TPOAb-positive with TSH levels greater than the pregnancy-specific reference range, or (2) TPOAb-negative with TSH levels greater than $10.0 \mathrm{mIU} / \mathrm{L}$. In these instances, a higher-than-usual initial LT4 dose could also be considered. Even when not pregnant, in women with sHypo who are hoping to conceive soon, LT4 could be started before conception, especially in TPOAb-positive subjects. Women of child-bearing age who have sHypo and TPOAb should also receive active LT4-Tx treatment, close follow-up, and education about the possible risks of sHypo for maternity.

The intermediate approach would cover all other cases. In this group, the clinical decision-making would be made based on the severity and persistence of sHypo, and patients' preferences. In relation to persistence, CAT (Hashimoto thyroiditis) is the main cause to focus on. A detailed diagnostic approach is important to discriminate CAT from transient or reversible conditions that are correctable by managing etiologic factors. The rationale for LT4-Tx could be set based on the possible benefit for CAT status itself, organ-specific considerations, and the poten- 
tial of adverse risks. Although conclusive, large-scale, prospective evidence is lacking, young, and middle-aged people with grade $2 \mathrm{sHypo}$, TPOAb positivity, and/or marked progression in follow-up thyroid function tests or the presence of cardiac risk factors [25] could usually be good candidates for LT4-Tx. LT4Tx might also be considered in patients with severe symptoms as a trial, though prescribing LT4 based only on patient symptoms seems to lack a clear rationale [69]. For individuals with CAT who are living in an iodine-rich area, education about iodine restriction (diet, medication, or health-related products containing high iodine levels) is essential. When the decision is made to treat sHypo, daily LT4-Tx is the treatment of choice. There is no evidence supporting the use of liothyronine (T3) or combined LT4/T3 for the treatment of sHypo. The initial dosage of LT4 should be individualized, approximating $1.5 \mu \mathrm{g} / \mathrm{kg} / \mathrm{day}$ (except in elderly patients) and should be increased gradually by $25 \mu \mathrm{g}$ /day every 14 to 21 days until a full replacement dose is reached. The goal of treatment is to normalize serum TSH levels. LT4 prescriptions have increased remarkably during the last decade and LT4 is most likely to be prescribed for the treatment of sHypo [107]. While over-treatment should be avoided, holding back LT4 initiation in patients who require it because of concerns of over-treatment is not advised [101].

\section{CONCLUSIONS}

sHypo is associated with adverse outcomes in terms of cardiovascular risk, metabolic conditions, and quality of life; however, the exact benefits of LT4-Tx in those with sHypo are unclear, especially in patients with grade 1 sHypo or elderly individuals. Given the paucity of evidence supporting the benefits of LT4Tx, it is reasonable to refrain from immediate LT4-Tx while closely monitoring most patients with sHypo, except in pregnant women or in progressive cases. However, there are indeed certain groups of patients for whom the benefits of LT4-Tx have been established; identifying these groups is an urgent task for future research [108]. Additionally, well-designed studies focused on younger patients with sHypo are needed because direct evidence is scant and therefore greater uncertainty remains [108]. For the management of sHypo, practical considerations include not only the serum TSH level and age, but also the burdens that come from overtreatment, regular visits, blood testing, medical costs, and emotional well-being [104]. Comprehensive assessments of all these issues would be essential to identify the true nature of sHypo and to establish an ideal management path.

\section{CONFLICTS OF INTEREST}

No potential conflict of interest relevant to this article was reported.

\section{ORCID}

Won Sang Yoo https://orcid.org/0000-0002-2314-4184

Hyun Kyung Chung https://orcid.org/0000-0001-5580-5808

\section{REFERENCES}

1. Braverman LE, Cooper DS, Kopp PA. Werner \& Ingbar's the thyroid. 11th ed. Philadelphia: Wolters Kluwer; 2021. Chapter 50, Subclinical hypothyroidism; p. 635-40.

2. Cooper DS. Clinical practice. Subclinical hypothyroidism. N Engl J Med 2001;345:260-5.

3. Biondi B, Cooper DS. The clinical significance of subclinical thyroid dysfunction. Endocr Rev 2008;29:76-131.

4. Hansen PS, Brix TH, Sorensen TI, Kyvik KO, Hegedus L. Major genetic influence on the regulation of the pituitarythyroid axis: a study of healthy Danish twins. J Clin Endocrinol Metab 2004;89:1181-7.

5. Kim WG, Kim WB, Woo G, Kim H, Cho Y, Kim TY, et al. Thyroid stimulating hormone reference range and prevalence of thyroid dysfunction in the Korean population: Korea National Health and Nutrition Examination Survey 2013 to 2015. Endocrinol Metab (Seoul) 2017;32:106-14.

6. Hollowell JG, Staehling NW, Flanders WD, Hannon WH, Gunter EW, Spencer CA, et al. Serum TSH, T(4), and thyroid antibodies in the United States population (1988 to 1994): National Health and Nutrition Examination Survey (NHANES III). J Clin Endocrinol Metab 2002;87:489-99.

7. Cooper DS, Biondi B. Subclinical thyroid disease. Lancet 2012;379:1142-54.

8. Mendes D, Alves C, Silverio N, Batel Marques F. Prevalence of undiagnosed hypothyroidism in Europe: a systematic review and meta-analysis. Eur Thyroid J 2019;8:13043.

9. Tunbridge WM, Evered DC, Hall R, Appleton D, Brewis M, Clark F, et al. The spectrum of thyroid disease in a community: the Whickham survey. Clin Endocrinol (Oxf) 1977;7: 481-93.

10. Nystrom E, Bengtsson C, Lindquist O, Noppa H, Lindstedt $\mathrm{G}$, Lundberg PA. Thyroid disease and high concentration of serum thyrotrophin in a population sample of women. A 
4-year follow-up. Acta Med Scand 1981;210:39-46.

11. Drinka PJ, Nolten WE. Prevalence of previously undiagnosed hypothyroidism in residents of a midwestern nursing home. South Med J 1990;83:1259-61, 1265.

12. Konno N, Yuri K, Taguchi H, Miura K, Taguchi S, Hagiwara $\mathrm{K}$, et al. Screening for thyroid diseases in an iodine sufficient area with sensitive thyrotrophin assays, and serum thyroid autoantibody and urinary iodide determinations. Clin Endocrinol (Oxf) 1993;38:273-81.

13. Canaris GJ, Manowitz NR, Mayor G, Ridgway EC. The Colorado thyroid disease prevalence study. Arch Intern Med 2000;160:526-34.

14. Hoogendoorn EH, Hermus AR, de Vegt F, Ross HA, Verbeek AL, Kiemeney LA, et al. Thyroid function and prevalence of anti-thyroperoxidase antibodies in a population with borderline sufficient iodine intake: influences of age and sex. Clin Chem 2006;52:104-11.

15. Perez-Campos Mayoral L, Hernandez-Huerta MT, Mayoral-Andrade G, Perez-Campo Mayoral E, Zenteno E, Martinez-Cruz R, et al. TSH levels in subclinical hypothyroidism in the 97.5th percentile of the population. Int J Endocrinol 2020;2020:2698627.

16. Chung JH. Evaluation of thyroid hormone levels and urinary iodine concentrations in Koreans based on the data from Korea National Health and Nutrition Examination Survey VI (2013 to 2015). Endocrinol Metab (Seoul) 2018; 33:160-3.

17. Biondi B. The normal TSH reference range: what has changed in the last decade? J Clin Endocrinol Metab 2013; 98:3584-7.

18. Surks MI, Hollowell JG. Age-specific distribution of serum thyrotropin and antithyroid antibodies in the US population: implications for the prevalence of subclinical hypothyroidism. J Clin Endocrinol Metab 2007;92:4575-82.

19. Chung JH. Update on thyroid hormone levels and thyroid dysfunction in the Korean population based on data from the Korea National Health and Nutrition Examination Survey VI (2013 to 2015). Endocrinol Metab (Seoul) 2020;35: 7-13.

20. Park SY, Kim HI, Oh HK, Kim TH, Jang HW, Chung JH, et al. Age- and gender-specific reference intervals of TSH and free T4 in an iodine-replete area: data from Korean National Health and Nutrition Examination Survey IV (20132015). PLoS One 2018; 13:e0190738.

21. Alexander EK, Pearce EN, Brent GA, Brown RS, Chen H, Dosiou C, et al. 2017 Guidelines of the American Thyroid
Association for the diagnosis and management of thyroid disease during pregnancy and the postpartum. Thyroid 2017;27:315-89.

22. Li C, Shan Z, Mao J, Wang W, Xie X, Zhou W, et al. Assessment of thyroid function during first-trimester pregnancy: what is the rational upper limit of serum TSH during the first trimester in Chinese pregnant women? J Clin Endocrinol Metab 2014;99:73-9.

23. Moon HW, Chung HJ, Park CM, Hur M, Yun YM. Establishment of trimester- specific reference intervals for thyroid hormones in Korean pregnant women. Ann Lab Med 2015;35:198-204.

24. Peeters RP. Subclinical hypothyroidism. N Engl J Med 2017;376:2556-65.

25. Biondi B, Cappola AR, Cooper DS. Subclinical hypothyroidism: a review. JAMA 2019;322:153-60.

26. Andersen S, Pedersen KM, Bruun NH, Laurberg P. Narrow individual variations in serum $\mathrm{T}(4)$ and $\mathrm{T}(3)$ in normal subjects: a clue to the understanding of subclinical thyroid disease. J Clin Endocrinol Metab 2002;87:1068-72.

27. Kim YA, Park YJ. Prevalence and risk factors of subclinical thyroid disease. Endocrinol Metab (Seoul) 2014;29:20-9.

28. Walsh JP, Bremner AP, Feddema P, Leedman PJ, Brown SJ, O'Leary P. Thyrotropin and thyroid antibodies as predictors of hypothyroidism: a 13-year, longitudinal study of a community-based cohort using current immunoassay techniques. J Clin Endocrinol Metab 2010;95:1095-104.

29. Moore DC. Natural course of 'subclinical' hypothyroidism in childhood and adolescence. Arch Pediatr Adolesc Med 1996;150:293-7.

30. Meyerovitch J, Rotman-Pikielny P, Sherf M, Battat E, Levy Y, Surks MI. Serum thyrotropin measurements in the community: five-year follow-up in a large network of primary care physicians. Arch Intern Med 2007;167:1533-8.

31. Volzke H, Alte D, Kohlmann T, Ludemann J, Nauck M, John $\mathrm{U}$, et al. Reference intervals of serum thyroid function tests in a previously iodine-deficient area. Thyroid 2005;15: 279-85.

32. Caron PJ, Nieman LK, Rose SR, Nisula BC. Deficient nocturnal surge of thyrotropin in central hypothyroidism. J Clin Endocrinol Metab 1986;62:960-4.

33. Kim TH, Kim KW, Ahn HY, Choi HS, Won H, Choi Y, et al. Effect of seasonal changes on the transition between subclinical hypothyroid and euthyroid status. J Clin Endocrinol Metab 2013;98:3420-9.

34. Hennessey JV, Espaillat R. Subclinical hypothyroidism: a 
historical view and shifting prevalence. Int J Clin Pract 2015;69:771-82.

35. Lee MW, Shin DY, Kim KJ, Hwang S, Lee EJ. The biochemical prognostic factors of subclinical hypothyroidism. Endocrinol Metab (Seoul) 2014;29:154-62.

36. Huber G, Staub JJ, Meier C, Mitrache C, Guglielmetti M, Huber P, et al. Prospective study of the spontaneous course of subclinical hypothyroidism: prognostic value of thyrotropin, thyroid reserve, and thyroid antibodies. J Clin Endocrinol Metab 2002;87:3221-6.

37. Diez JJ, Iglesias P. Spontaneous subclinical hypothyroidism in patients older than 55 years: an analysis of natural course and risk factors for the development of overt thyroid failure. J Clin Endocrinol Metab 2004;89:4890-7.

38. Konno N, Makita H, Yuri K, Iizuka N, Kawasaki K. Association between dietary iodine intake and prevalence of subclinical hypothyroidism in the coastal regions of Japan. J Clin Endocrinol Metab 1994;78:393-7.

39. Cho NH, Choi HS, Kim KW, Kim HL, Lee SY, Choi SH, et al. Interaction between cigarette smoking and iodine intake and their impact on thyroid function. Clin Endocrinol (Oxf) 2010;73:264-70.

40. Willms A, Bieler D, Wieler H, Willms D, Kaiser KP, Schwab R. Correlation between sonography and antibody activity in patients with Hashimoto thyroiditis. J Ultrasound Med 2013;32:1979-86.

41. Mariotti S, Franceschi C, Cossarizza A, Pinchera A. The aging thyroid. Endocr Rev 1995;16:686-715.

42. Boucai L, Hollowell JG, Surks MI. An approach for development of age-, gender-, and ethnicity-specific thyrotropin reference limits. Thyroid 2011;21:5-11.

43. Gussekloo J, van Exel E, de Craen AJ, Meinders AE, Frolich M, Westendorp RG. Thyroid status, disability and cognitive function, and survival in old age. JAMA 2004;292: 2591-9.

44. Hyland KA, Arnold AM, Lee JS, Cappola AR. Persistent subclinical hypothyroidism and cardiovascular risk in the elderly: the cardiovascular health study. J Clin Endocrinol Metab 2013;98:533-40.

45. Pasqualetti G, Pagano G, Rengo G, Ferrara N, Monzani F. Subclinical hypothyroidism and cognitive impairment: systematic review and meta-analysis. J Clin Endocrinol Metab 2015;100:4240-8.

46. Stott DJ, Rodondi N, Kearney PM, Ford I, Westendorp RGJ, Mooijaart SP, et al. Thyroid hormone therapy for older adults with subclinical hypothyroidism. N Engl J Med
2017;376:2534-44.

47. Lazarus J, Brown RS, Daumerie C, Hubalewska-Dydejczyk A, Negro R, Vaidya B. 2014 European Thyroid Association guidelines for the management of subclinical hypothyroidism in pregnancy and in children. Eur Thyroid J 2014;3:76-94.

48. Kang MJ, Hwang IT, Chung HR. Excessive iodine intake and subclinical hypothyroidism in children and adolescents aged 6-19 years: results of the sixth Korean National Health and Nutrition Examination Survey, 2013-2015. Thyroid 2018;28:773-9.

49. Cerbone M, Bravaccio C, Capalbo D, Polizzi M, Wasniewska M, Cioffi D, et al. Linear growth and intellectual outcome in children with long-term idiopathic subclinical hypothyroidism. Eur J Endocrinol 2011;164:591-7.

50. Wasniewska M, Aversa T, Salerno M, Corrias A, Messina MF, Mussa A, et al. Five-year prospective evaluation of thyroid function in girls with subclinical mild hypothyroidism of different etiology. Eur J Endocrinol 2015;173:801-8.

51. Aversa T, Valenzise M, Corrias A, Salerno M, De Luca F, Mussa A, et al. Underlying Hashimoto's thyroiditis negatively affects the evolution of subclinical hypothyroidism in children irrespective of other concomitant risk factors. Thyroid 2015;25:183-7.

52. Lee YJ, Jung SY, Jung HW, Kim SY, Lee YA, Lee SY, et al. Unfavorable course of subclinical hypothyroidism in children with Hashimoto's thyroiditis compared to those with isolated non-autoimmune hyperthyrotropinemia. J Korean Med Sci 2017;32:124-9.

53. Crisafulli G, Aversa T, Zirilli G, Pajno GB, Corica D, De Luca F, et al. Subclinical hypothyroidism in children: when a replacement hormonal treatment might be advisable. Front Endocrinol (Lausanne) 2019;10:109.

54. Arafah BM. Increased need for thyroxine in women with hypothyroidism during estrogen therapy. N Engl J Med 2001;344:1743-9.

55. Glinoer D. The regulation of thyroid function in pregnancy: pathways of endocrine adaptation from physiology to pathology. Endocr Rev 1997;18:404-33.

56. Stricker R, Echenard M, Eberhart R, Chevailler MC, Perez $\mathrm{V}$, Quinn FA, et al. Evaluation of maternal thyroid function during pregnancy: the importance of using gestational agespecific reference intervals. Eur J Endocrinol 2007;157: 509-14.

57. Stagnaro-Green A, Abalovich M, Alexander E, Azizi F, Mestman J, Negro R, et al. Guidelines of the American 
Thyroid Association for the diagnosis and management of thyroid disease during pregnancy and postpartum. Thyroid 2011;21:1081-125.

58. Maraka S, Ospina NM, O’Keeffe DT, Espinosa De Ycaza AE, Gionfriddo MR, Erwin PJ, et al. Subclinical hypothyroidism in pregnancy: a systematic review and meta-analysis. Thyroid 2016;26:580-90.

59. Consortium on Thyroid and Pregnancy-Study Group on Preterm Birth, Korevaar TIM, Derakhshan A, Taylor PN, Meima M, Chen L, et al. Association of thyroid function test abnormalities and thyroid autoimmunity with preterm birth: a systematic review and meta-analysis. JAMA 2019; 322:632-41.

60. Correia N, Mullally S, Cooke G, Tun TK, Phelan N, Feeney $\mathrm{J}$, et al. Evidence for a specific defect in hippocampal memory in overt and subclinical hypothyroidism. J Clin Endocrinol Metab 2009;94:3789-97.

61. Zhu DF, Wang ZX, Zhang DR, Pan ZL, He S, Hu XP, et al. fMRI revealed neural substrate for reversible working memory dysfunction in subclinical hypothyroidism. Brain 2006;129(Pt 11):2923-30.

62. Jorde R, Waterloo K, Storhaug H, Nyrnes A, Sundsfjord J, Jenssen TG. Neuropsychological function and symptoms in subjects with subclinical hypothyroidism and the effect of thyroxine treatment. J Clin Endocrinol Metab 2006;91:14553.

63. Loh HH, Lim LL, Yee A, Loh HS. Association between subclinical hypothyroidism and depression: an updated systematic review and meta-analysis. BMC Psychiatry 2019; 19:12.

64. Zhao T, Chen BM, Zhao XM, Shan ZY. Subclinical hypothyroidism and depression: a meta-analysis. Transl Psychiatry 2018;8:239.

65. Demartini B, Ranieri R, Masu A, Selle V, Scarone S, Gambini O. Depressive symptoms and major depressive disorder in patients affected by subclinical hypothyroidism: a cross-sectional study. J Nerv Ment Dis 2014;202:603-7.

66. Park YJ, Lee EJ, Lee YJ, Choi SH, Park JH, Lee SB, et al. Subclinical hypothyroidism $(\mathrm{SCH})$ is not associated with metabolic derangement, cognitive impairment, depression or poor quality of life (QoL) in elderly subjects. Arch Gerontol Geriatr 2010;50:e68-73.

67. Kim JS, Zhang Y, Chang Y, Ryu S, Guallar E, Shin YC, et al. Subclinical hypothyroidism and incident depression in young and middle-age adults. J Clin Endocrinol Metab 2018;103:1827-33.
68. Panicker V, Evans J, Bjoro T, Asvold BO, Dayan CM, Bjerkeset $\mathrm{O}$. A paradoxical difference in relationship between anxiety, depression and thyroid function in subjects on and not on T4: findings from the HUNT study. Clin Endocrinol (Oxf) 2009;71:574-80.

69. Feller M, Snel M, Moutzouri E, Bauer DC, de Montmollin M, Aujesky D, et al. Association of thyroid hormone therapy with quality of life and thyroid-related symptoms in patients with subclinical hypothyroidism: a systematic review and meta-analysis. JAMA 2018;320:1349-59.

70. Mooijaart SP, Du Puy RS, Stott DJ, Kearney PM, Rodondi $\mathrm{N}$, Westendorp RGJ, et al. Association between levothyroxine treatment and thyroid-related symptoms among adults aged 80 years and older with subclinical hypothyroidism. JAMA 2019;322:1977-86.

71. Oiwa A, Minemura K, Nishio SI, Yamazaki M, Komatsu M. Implications of thyroid autoimmunity in infertile women with subclinical hypothyroidism in the absence of both goiter and anti-thyroid antibodies: lessons from three cases. Endocr J 2019;66:193-8.

72. Chen X, Zhang N, Cai Y, Shi J. Evaluation of left ventricular diastolic function using tissue Doppler echocardiography and conventional doppler echocardiography in patients with subclinical hypothyroidism aged $<60$ years: a metaanalysis. J Cardiol 2013;61:8-15.

73. Owen PJ, Sabit R, Lazarus JH. Thyroid disease and vascular function. Thyroid 2007;17:519-24.

74. Gao N, Zhang W, Zhang YZ, Yang Q, Chen SH. Carotid intima-media thickness in patients with subclinical hypothyroidism: a meta-analysis. Atherosclerosis 2013;227:18-25.

75. Hak AE, Pols HA, Visser TJ, Drexhage HA, Hofman A, Witteman JC. Subclinical hypothyroidism is an independent risk factor for atherosclerosis and myocardial infarction in elderly women: the Rotterdam Study. Ann Intern Med 2000;132:270-8.

76. Singh S, Duggal J, Molnar J, Maldonado F, Barsano CP, Arora R. Impact of subclinical thyroid disorders on coronary heart disease, cardiovascular and all- cause mortality: a meta-analysis. Int J Cardiol 2008;125:41-8.

77. Moon S, Kim MJ, Yu JM, Yoo HJ, Park YJ. Subclinical hypothyroidism and the risk of cardiovascular disease and allcause mortality: a meta-analysis of prospective cohort studies. Thyroid 2018;28:1101-10.

78. Kim H, Kong SH, Moon JH, Kim SY, Park KH, Kim JS, et al. Subclinical hypothyroidism affects the long-term outcomes of patients who undergo coronary artery bypass 
grafting surgery but not heart valve surgery. Endocrinol Metab (Seoul) 2020;35:308-18.

79. Baumgartner C, da Costa BR, Collet TH, Feller M, Floriani C, Bauer DC, et al. Thyroid function within the normal range, subclinical hypothyroidism, and the risk of atrial fibrillation. Circulation 2017;136:2100-16.

80. Gencer B, Collet TH, Virgini V, Bauer DC, Gussekloo J, Cappola AR, et al. Subclinical thyroid dysfunction and the risk of heart failure events: an individual participant data analysis from 6 prospective cohorts. Circulation 2012;126: 1040-9.

81. Chaker L, Baumgartner C, den Elzen WP, Ikram MA, Blum MR, Collet TH, et al. Subclinical hypothyroidism and the risk of stroke events and fatal stroke: an individual participant data analysis. J Clin Endocrinol Metab 2015;100: 2181-91.

82. Collet TH, Bauer DC, Cappola AR, Asvold BO, Weiler S, Vittinghoff E, et al. Thyroid antibody status, subclinical hypothyroidism, and the risk of coronary heart disease: an individual participant data analysis. J Clin Endocrinol Metab 2014;99:3353-62.

83. Rodondi N, den Elzen WP, Bauer DC, Cappola AR, Razvi $\mathrm{S}$, Walsh JP, et al. Subclinical hypothyroidism and the risk of coronary heart disease and mortality. JAMA 2010;304: 1365-74.

84. Redford C, Vaidya B. Subclinical hypothyroidism: should we treat? Post Reprod Health 2017;23:55-62.

85. Jabbar A, Ingoe L, Junejo S, Carey P, Addison C, Thomas H, et al. Effect of levothyroxine on left ventricular ejection fraction in patients with subclinical hypothyroidism and acute myocardial infarction: a randomized clinical trial. JAMA 2020;324:249-58.

86. Parsaik AK, Singh B, Roberts RO, Pankratz S, Edwards $\mathrm{KK}$, Geda YE, et al. Hypothyroidism and risk of mild cognitive impairment in elderly persons: a population-based study. JAMA Neurol 2014;71:201-7.

87. Rieben C, Segna D, da Costa BR, Collet TH, Chaker L, Aubert CE, et al. Subclinical thyroid dysfunction and the risk of cognitive decline: a meta-analysis of prospective cohort studies. J Clin Endocrinol Metab 2016;101:4945-54.

88. Akintola AA, Jansen SW, van Bodegom D, van der Grond J, Westendorp RG, de Craen AJ, et al. Subclinical hypothyroidism and cognitive function in people over 60 years: a systematic review and meta-analysis. Front Aging Neurosci 2015;7:150.

89. Blum MR, Bauer DC, Collet TH, Fink HA, Cappola AR, da Costa BR, et al. Subclinical thyroid dysfunction and fracture risk: a meta-analysis. JAMA 2015;313:2055-65.

90. Segna D, Bauer DC, Feller M, Schneider C, Fink HA, Aubert CE, et al. Association between subclinical thyroid dysfunction and change in bone mineral density in prospective cohorts. J Intern Med 2018;283:56-72.

91. Siru R, Alfonso H, Chubb SAP, Golledge J, Flicker L, Yeap BB. Subclinical thyroid dysfunction and circulating thyroid hormones are not associated with bone turnover markers or incident hip fracture in older men. Clin Endocrinol (Oxf) 2018;89:93-9.

92. Virgini VS, Rodondi N, Cawthon PM, Harrison SL, Hoffman AR, Orwoll ES, et al. Subclinical thyroid dysfunction and frailty among older men. J Clin Endocrinol Metab 2015;100:4524-32.

93. Virgini VS, Wijsman LW, Rodondi N, Bauer DC, Kearney PM, Gussekloo J, et al. Subclinical thyroid dysfunction and functional capacity among elderly. Thyroid 2014;24:20814.

94. Da Costa AB, Pellizzari C, Carvalho GA, Sant'Anna BC, Montenegro RL, Zammar Filho RG, et al. High prevalence of subclinical hypothyroidism and nodular thyroid disease in patients on hemodialysis. Hemodial Int 2016;20:31-7.

95. Shin DH, Lee MJ, Lee HS, Oh HJ, Ko KI, Kim CH, et al. Thyroid hormone replacement therapy attenuates the decline of renal function in chronic kidney disease patients with subclinical hypothyroidism. Thyroid 2013;23:654-61.

96. Rhee CM, Kim S, Gillen DL, Oztan T, Wang J, Mehrotra R, et al. Association of thyroid functional disease with mortality in a national cohort of incident hemodialysis patients. J Clin Endocrinol Metab 2015;100:1386-95.

97. Meuwese CL, van Diepen M, Cappola AR, Sarnak MJ, Shlipak MG, Bauer DC, et al. Low thyroid function is not associated with an accelerated deterioration in renal function. Nephrol Dial Transplant 2019;34:650-9.

98. Posadas-Romero C, Jorge-Galarza E, Posadas-Sanchez R, Acuna-Valerio J, Juarez-Rojas JG, Kimura-Hayama E, et al. Fatty liver largely explains associations of subclinical hypothyroidism with insulin resistance, metabolic syndrome, and subclinical coronary atherosclerosis. Eur J Endocrinol 2014;171:319-25.

99. Liu L, Yu Y, Zhao M, Zheng D, Zhang X, Guan Q, et al. Benefits of levothyroxine replacement therapy on nonalcoholic fatty liver disease in subclinical hypothyroidism patients. Int J Endocrinol 2017;2017:5753039.

100. Garber JR, Cobin RH, Gharib H, Hennessey JV, Klein I, 
Mechanick JI, et al. Clinical practice guidelines for hypothyroidism in adults: cosponsored by the American Association of Clinical Endocrinologists and the American Thyroid Association. Endocr Pract 2012;18:988-1028.

101. Pearce SH, Brabant G, Duntas LH, Monzani F, Peeters RP, Razvi S, et al. 2013 ETA guideline: management of subclinical hypothyroidism. Eur Thyroid J 2013;2:215-28.

102. Smith MW. The 10 most-prescribed and top-selling medications [Internet]. New York: WebMD; 2015 [cited 2021 Jun 1]. Available from: https://www.webmd.com/drugmedication/news/20150508/most-prescribed-top-sellingdrugs.

103. National Institute for Health and Care Excellence. Clinical Knowledge summaries. Subclinical hypothyroidism (non-pregnant) [Internet]. London: NICE; 2018 [cited 2021 Jun 1]. Available from: https://cks.nice.org.uk/hypothyroidism\#!scenario:1.
104. Bekkering GE, Agoritsas T, Lytvyn L, Heen AF, Feller M, Moutzouri E, et al. Thyroid hormones treatment for subclinical hypothyroidism: a clinical practice guideline. BMJ 2019;365:12006.

105. Ruggeri RM, Trimarchi F, Biondi B. Management of endocrine disease: 1-thyroxine replacement therapy in the frail elderly: a challenge in clinical practice. Eur J Endocrinol 2017;177:R199-217.

106. Cooper DS. Thyroid disease in the oldest old: the exception to the rule. JAMA 2004;292:2651-4.

107. Calissendorff J, Falhammar H. To treat or not to treat subclinical hypothyroidism, what is the evidence? Medicina (Kaunas) 2020;56:40.

108. Taylor P, Bianco AC. Urgent need for further research in subclinical hypothyroidism. Nat Rev Endocrinol 2019;15: 503-4. 